\title{
APLICAÇÕES CLÍNICAS E ÉTICAS DA EUTANÁSIA EM PEQUENOS ANIMAIS
}

AGOSTINHO, Janaina Jorge ${ }^{1}$

LÉGA, Elzylene²

Recebido em: 2009-02-06

Aprovado em: 2009-04-29

Issue DOI: $10.3738 / 1982.2278 .163$

RESUMO: O presente trabalho traz a conscientização sobre a eutanásia, seus métodos de aplicação e agentes utilizados, em quais casos deve ser realizada e que agentes são proibidos, além de ressaltar a dedicação e os cuidados na hora de praticar a ação, já que a palavra eutanásia, em grego, significa Boa Morte. Além disso, enfatiza a clara posição ética e a responsabilidade do médico veterinário ao recomendar a eutanásia, esclarecendo quando, porque e como ela deve ser realizada, não causando estresse e sofrimento ao animal, e seu posicionamento moral junto ao proprietário. Ressalta-se ainda, que o médico veterinário não deve delegar a responsabilidade da realização da eutanásia a uma pessoa não capacitada, o que poderá gerar erro ou não atender aos requisitos básicos para a sua realização. Foram entrevistados quarenta e um profissionais médicos veterinários escolhidos aleatoriamente e distribuídos por sete cidades da região, sendo submetidos a um questionário com perguntas relacionadas ao tempo em que trabalha com pequenos animais, quais os procedimentos para se realizar a eutanásia, quais suas indicações e a sua incidência. Concluiu-se que este índice não é alto, sendo submetido à eutanásia animais em situações extremamente incompatíveis com a vida.

Palavras-chave: Eutanásia. Cão. Gato.

SUMMARY: This work brings us awareness about euthanasia, its agents and methods of application used, in which cases should be done and what agents are prohibited, as well as highlight the dedication and care in the hours of practice to share, since the word Euthanasia in Greek, means Good Death. Moreover, the clear position emphasizes ethics and responsibility of the veterinarian to recommend euthanasia, explaining when, why and how it should be done, not causing stress and suffering to the animal, and its moral position with the owner. It is also a veterinarian must not delegate the task of carrying out euthanasia on a person not trained, which can generate error or not meet the basic requirements for its implementation. We interviewed forty-a veterinary medical professionals selected randomly and spread over seven cities in the region, which were submitted to a questionnaire related to when it works with small animals, which the procedures to carry out euthanasia, its indications and incidence. It was concluded that this index is low, being subjected to euthanasia animals in situations extremely incompatible with life.

Keywords: Euthanasia. Dog. Cat.

1 Graduanda do Curso de Medicina Veterinária da Faculdade Dr. Francisco Maeda - FAFRAM - Ituverava, SP. 2 Dra. Prof. ${ }^{a}$ do curso de Medicina Veterinária da Faculdade Dr. Francisco Maeda - FAFRAM - Ituverava, SP. 


\section{INTRODUÇÃO}

Segundo Rivera et al. (2006), a eutanásia é o ato de matar animais por meio de métodos que induzam à rápida inconsciência e morte dos mesmos sem sofrimento, pois a própria etmologia do termo, originado do grego eu (boa) e thanatos (morte) já indica que a morte deve ocorrer sem angústia nem sofrimento.

Figueiredo; Araújo (2001) ressaltaram em se tratando de um assunto polêmico e pouco abordado na matriz curricular da maioria dos estabelecimentos de ensino no Brasil, a questão nunca foi amplamente debatida, tampouco houve normatização sobre tais ações, o que ocasionou uma diversidade imensa de métodos e procedimentos, por vezes altamente condenáveis. Esta situação nos coloca frente à necessidade urgente de explanarmos o assunto de modo técnico e realista, para que ao menos, sejam interrompidas as ações irregulares que colocam em questionamento não só a qualificação dos profissionais que as executam, bem como o respeito dado às espécies animais sob os nossos cuidados. É neste contexto que temos a responsabilidade de assumir, como profissionais médicos veterinários e como seres humanos os quais somos que, se a vida de um animal está para ser tirada, que seja feito com o mais alto grau de respeito ao animal sob os nossos cuidados.

De acordo com Massone (2003), existem várias maneiras de se praticar a eutanásia; entretanto, ressalta-se que os únicos métodos a serem empregados são aqueles humanitários e que não causam dor, asfixia ou desconforto o qual perdure durante o sacrifício, sendo, portanto considerado como métodos mais aceitáveis aqueles que causam paradas respiratória e cardíaca simultaneamente.

Segundo Rivera et al. (2006), no momento de recomendar a eutanásia, o médico veterinário deverá demonstrar clara posição ética, sendo de sua responsabilidade e competência a avaliação da necessidade da eutanásia, de como deve ser executada, quais são os métodos apropriados, que procedimentos são proibidos, como avaliar a cessação dos sinais vitais, não delegando o procedimento a outra pessoa, e também demonstrar segurança e falar claramente sobre o assunto com o cliente.

Oliveira et al. (2002) referiram que a eutanásia pode ser vista sob várias perspectivas, sendo que, para o animal ela deve ser indolor, produzir inconsciência instantânea e morte rápida; para o executante, o método deve ser seguro e não provocar choques emocionais; para a pesquisa, o método escolhido não deve resultar em modificações biológicas e ou histológicas incompatíveis com os dados esperados do ensaio; para a gestão, a eutanásia deve ser praticada nas melhores condições econômicas, tanto no que concerne ao equipamento e locais, bem como os meios utilizados.

De acordo com Figueiredo; Araújo (2001), para que se evite situações de estresse e angústia nos animais que serão submetidos ao procedimento da eutanásia, tais atos deverão ocorrer em ambiente seguro, silencioso e totalmente isolados de outros animais, principalmente, os da mesma espécie, uma vez que os animais liberam feromônios que indicam seu estado de 
angústia e medo, e tal comportamento é imediatamente percebido pelos outros animais.

Ainda segundo Figueiredo; Araújo (2001), considerando-se a questão legal da eutanásia, recomenda-se que todo profissional médico veterinário somente realize o procedimento após anuência, por escrito, do proprietário do animal, e nas situações onde este não for localizado ou mesmo inexistente, tal procedimento deverá estar justificado em legislação vigente, fornecendo desta forma amparo legal aos profissionais de Centros de Controle de Zoonoses.

De acordo com Rivera et al. (2006), dentre algumas situações em que pode ser necessária a indicação da eutanásia, podemos citar os animais com doenças terminais, animais portadores de doenças zoonóticas, como leishmaniose e raiva, animais vítimas de acidentes de trânsito ou outros tipos de acidentes, ou como controle de excesso de animais abandonados por seus donos e que se continuarem nas ruas poderão ocasionar sérios problemas de saúde, mas essa questão sofre pressões da opinião pública no sentido de salvar ao invés de destruir os animais.

Segundo Spinosa et al. (2002) há, também, situações em que o clínico veterinário é solicitado a praticar a eutanásia por outras razões que envolvem o interesse do proprietário do animal, alegando, na maioria das vezes, razões de ordem econômica, conveniência pessoal, comportamento indesejável ou, ainda, abandono do animal.

Frank (2004) enfatizou que a superpopulação de animais de companhia é um problema que acarreta significativos custos humanos, e que só podem ser abordados através de ação humana, como a castração e a adoção, reduzindo assim as taxas de eutanásia e a superpopulação de animais.

Hughes et al. (2002) também, enfatizaram que um programa de esterilização de cães e gatos tem por objetivo reduzir o número de animais saudáveis eutanasiados, tendo diminuído este número após a implantação do programa e aumentado o número de cirurgias de castração e adoção desses animais.

Heiblum; Tejeda (2007) afirmaram que os papéis de animais de companhia têm se expandido, e o animal de estimação é visto como um membro da família, prestador de apoio social e emocional, e, nos casos de cães de serviço, prestador de assistência aos proprietários com necessidades especiais, e suas mortes podem ser extremamente dolorosas para suas famílias. Em situações críticas ou terminal, o médico veterinário tem o importante papel de manter o proprietário informado sobre as decisões relativas às opções de tratamento ou sobre a prática da eutanásia, se necessário. Uma vez que o proprietário decida pela eutanásia, deve-se considerar quando será realizado o procedimento, se os familiares estarão presentes, e contar com o apoio do médico veterinário para que não haja um sentimento de culpa pelo proprietário por ter optado pela eutanásia, uma vez que foi feito o melhor para o animal.

De acordo com Lakestani et al. (2005), existe ainda a questão de animais abandonados e eutanasiados após agressão, constituindo um problema de saúde pública frequentemente relatado, onde as principais vítimas são crianças que, além dos problemas físicos e psicológicos obtidos, podem ter problemas emocionais devido à perda do animal.

Algumas raças de cães e gatos apresentam uma maior predisposição a desenvolver 
surdez hereditária uni ou bilateral, onde são realizados testes específicos para sua constatação, sendo que alguns animais surdos ou parcialmente surdos são treinados para serem bons animais de estimação, enquanto outros, por problemas comportamentais muitas vezes associados ao estresse e a ansiedade são submetidos à eutanásia (BIRCH, 2004; FATJO et al., 2006).

Piirainen; Taponen (2003) mencionaram que uma das principais indicações da eutanásia é a idade avançada do animal, neoplasias, doenças do sistema músculo-esquelético e problemas comportamentais, sendo a agressividade a causa mais comum.

Johannes et al. (2007) informaram que alguns gatos com hemangiossarcoma visceral foram submetidos à eutanásia, devido ao prognóstico desfavorável da doença.

Dennler et al. (2007) também, citou o hemangiossarcoma como um prognóstico desfavorável, submetendo um cão a uma grave e progressiva ataxia, onde este animal foi eutanasiado e, em sua necrópsia, encontrou-se um metastático hemangiossarcoma no cérebro, causando sangramento agudo.

Figueiredo; Araújo (2001) classificaram a eutanásia animal de acordo com o método empregado, dividindo o procedimento em eutanásia por métodos físicos ou químicos, que por sua vez podem ser decorrentes do uso de substâncias inalantes ou substâncias injetáveis, os quais são indicados como procedimento mais seguro e humanitário existente, se forem obedecidas as especificações dos produtos utilizados, quanto à dose, via de administração e intervalo de tempo entre um fármaco e outro, no caso das associações medicamentosas.

Oliveira et al. (2002) enfatizaram que os métodos físicos devem causar a perda imediata de consciência, mediante trauma físico cerebral e podem ser necessários, quando as utilizações de fármacos comprometem os resultados principais da pesquisa, enquanto os métodos químicos têm por base o uso de substâncias que prontamente produzem a inconsciência e a morte dos animais, em função de sobredosagem, a exemplo dos anestésicos utilizados na anestesia geral. Ambos os métodos requerem treinamento especializado para a contenção, manejo de instrumentos e manipulação dos fármacos a serem utilizados, buscando-se a precisão e a rapidez no procedimento, de modo a minimizar o estresse e abreviar a morte dos animais.

Segundo Spinosa et al. (2002), as características desejáveis de um agente para eutanásia devem promover indução suave, não causando alterações comportamentais que indiquem dor ou ansiedade, causar indução rápida, onde a inconsciência e a morte ocorram de forma instantânea ou dentro de pouquíssimos minutos, ser seguro e de fácil emprego para o profissional o qual manipula o agente, não deixar resíduos ou lesões teciduais que possam prejudicar a necrópsia e ser economicamente viável. São agentes utilizados na eutanásia: os barbitúricos, considerados os mais próximos do ideal, pois são classificados como depressores gerais do sistema nervoso central; o T-61 $1^{3}$, indicado para uso intravenoso, causa severa depressão do sistema nervoso central, hipóxia e colapso circulatório; os anestésicos inalatórios, utilizados na eutanásia de pequenos animais devido à dificuldade do uso da via intravenosa nestas espécies; o dióxido de carbono, que é um gás anestésico recomendado para a insensibilização de suínos e aves

3 T-61: Associação do anestésico geral embutramida, do agente curarizante mebezônio e do anestésico local tetracaína. Laboratório Hoechst Roussel Vet.

Nucleus Animalium, v.1, n.1, maio 2009 
antes do abate e que pode ser empregado em câmaras para a eutanásia da maioria dos animais de laboratório; a eletricidade e a pistola pneumática, que são indicadas para a insensibilização do animal antes do abate; e as armas de fogo, que são indicadas nos casos de abate sanitário para erradicar ou controlar epizootias ou zoonoses ou na eutanásia de animais extremamente agressivos. De acordo com os agentes que não devem ser usados para a eutanásia, destacam-se os agentes curarizantes, como a galamina, que causam a morte por paralisia funcional dos músculos respiratórios, levando à anóxia cerebral; a estricnina, que é um estimulante medular que causa convulsões sem alterar a consciência, onde a morte ocorre devido a incapacidade funcional da musculatura respiratória, que se encontra em rigidez tônica; drogas de ação no coração, sejam estimulantes (digitálico, cálcio) ou depressores (íons potássio e magnésio) do miocárdio, que causam a morte por parada cardíaca, porém não deprimem a consciência e não são analgésicos; gás ou solução de cianeto, que causa a morte por anóxia histotóxica, onde o animal desenvolve rapidamente um quadro de coma, choque, crises convulsivas e parada cardiorrespiratória, além de ser extremamente tóxico, oferecendo risco para o operador; a embolia gasosa e anestésicos voláteis por via intravenosa, onde a morte é precedida, geralmente, de excitação acentuada, dor e vocalização, e por último a exsanguinação ou sangria, admitida quando precedida da insensibilização do animal e visa ao bom processamento tecnológico da carne.

\section{MATERIAL E MÉTODOS}

Foram entrevistados 41 profissionais médicos veterinários, os quais foram submetidos a um questionário (anexo 01) com perguntas relacionadas ao tempo de formado; ao tempo em que trabalham com pequenos animais; aos procedimentos de eutanásia e suas indicações; sobre a melhor forma de abordar o proprietário, quando há necessidade de realizar a eutanásia; sobre o destino dado ao corpo do animal eutanasiado e quem deve se responsabilizar por ele; se o proprietário poderá acompanhar o procedimento; se há termo de autorização documentado para que se realize o procedimento e se, em caso de grande incidência de abandono de animais, a eutanásia seria uma alternativa justificável.

\section{RESULTADOS E DISCUSSÃO}

Os quarenta e um profissionais entrevistados ${ }^{4}$ atuavam na área de Clínica de Pequenos Animais nas cidades de Araraquara, Barretos, Campinas, Ituverava, Miguelópolis, Mirassol e Ribeirão Preto, foram escolhidos de forma aleatória (Tabela 1).

$4 \quad$ Os dados constantes nas tabelas são resultado de entrevistas realizada como Trabalho de Conclusão de Curso de Graduação em Medicina Veterinária da Faculdade Dr. Francisco Maeda - FAFRAM. Ituverava. 2008.

Nucleus Animalium, v.1, n.1, maio 2009 
TABELA 1: Número de profissionais médicos veterinários entrevistados durante pesquisa sobre procedimentos de eutanásia na Clínica de Pequenos Animais.

\begin{tabular}{lcc}
\hline Município & Número de Profissionais & Porcentagem \\
\hline Araraquara & 8 & $20 \%$ \\
Barretos & 14 & $34 \%$ \\
Campinas & 1 & $2 \%$ \\
Ituverava & 9 & $22 \%$ \\
Miguelópolis & 4 & $10 \%$ \\
Mirassol & 1 & $2 \%$ \\
Ribeirão Preto & 4 & $10 \%$ \\
TOTAL & 41 & $\mathbf{1 0 0 \%}$
\end{tabular}

Dos 41 profissionais médicos veterinários entrevistados, 20\% atuavam na cidade de Araraquara, 34\% em Barretos, 2\% em Campinas, 22\% em Ituverava, 10\% em Miguelópolis, 2\% em Mirassol e 10\% em Ribeirão Preto, todas localizadas no estado de São Paulo.

TABELA 2: Tempo de graduação de profissionais médicos veterinários entrevistados.

\begin{tabular}{lcc}
\hline Tempo de Graduado & Número de Profissionais & Porcentagem \\
Até 2 anos & 9 & $22 \%$ \\
$2-5$ anos & 10 & $24 \%$ \\
$6-10$ anos & 6 & $15 \%$ \\
$11-15$ anos & 11 & $27 \%$ \\
Acima de 15 anos & 5 & $12 \%$ \\
TOTAL & 41 & $\mathbf{1 0 0} \%$ \\
\hline
\end{tabular}

Com relação ao tempo de graduação dos profissionais entrevistados (Tabela 2), 22\% têm até 02 anos de formado, $24 \%$ de 2 a 5 anos, $15 \%$ de 6 a 10 anos, $27 \%$ de 11 a 15 anos, o que foi considerado a maioria, e $12 \%$ acima de 15 anos, sendo que não foi correlacionado o tempo de graduado com a prática da eutanásia, nem foi encontrado referência semelhante na literatura consultada.

TABELA 3: Tempo de atuação na área de Clínica de Pequenos Animais dos profissionais médicos veterinários entrevistados.

\begin{tabular}{lcc}
\hline Tempo de Atuação & Número de Profissionais & Porcentagem \\
\hline Até 2 anos & 10 & $24 \%$ \\
$2-5$ anos & 8 & $20 \%$ \\
$6-10$ anos & 10 & $24 \%$ \\
$11-15$ anos & 7 & $17 \%$ \\
Acima de 15 anos & 5 & $12 \%$ \\
Não responderam & 1 & $2 \%$ \\
TOTAL & $\mathbf{4 1}$ & $\mathbf{1 0 0 \%}$
\end{tabular}


Conforme a tabela 3, a maioria dos profissionais entrevistados tinham até 2 anos ou entre 6 e 10 anos de atuação na área de Pequenos Animais, contribuindo com 24\% cada um. Ainda pode ser observado que $20 \%$ dos profissionais atuavam na área de 2 a 5 anos; $17 \%$ de 11 a 15 anos, $12 \%$ acima de 15 anos e 2\% não responderam. Dessa forma, pela amostragem, não foi possível realizar correlação entre o tempo de atuação na área e a prática da eutanásia.

TABELA 4: Indicações para a realização da eutanásia na Clínica de Pequenos Animais citadas por profissionais médicos veterinários entrevistados.

\begin{tabular}{lcc} 
Indicações para a eutanásia & Número de indicações & Porcentagem \\
\hline Animais agressivos & 1 & $1 \%$ \\
Cinomose & 14 & $18 \%$ \\
Insuficiência renal crônica & 3 & $4 \%$ \\
Neoplasias & 9 & $12 \%$ \\
Outras doenças incuráveis ou em estado terminal & 36 & $46 \%$ \\
Patologias neurológicas irreversíveis & 2 & $3 \%$ \\
Proprietário sem condições financeiras para o tratamento & 4 & $5 \%$ \\
Zoonoses & 9 & $12 \%$ \\
\hline TOTAL DE INDICAÇÕES & $\mathbf{7 8}$ & $\mathbf{1 0 0} \%$ \\
\hline
\end{tabular}

Segundo Lakestani et al. (2005), um problema comportamental é um fator que pode determinar a realização da eutanásia. Birch (2004) e Fatjo et al. (2006), enfatizaram que alguns problemas comportamentais estão associados ao estresse e a ansiedade, tornando o animal agressivo, e pode até ocorrer o abandono deste e, posteriormente, sua eutanásia.

Piirainen; Taponen (2003) mencionaram que a idade avançada do animal, neoplasias, doenças do sistema músculo-esquelético e agressividade são fatores importantes ao se optar pela eutanásia. Rivera et al. (2006) citaram que, dentre algumas situações nas quais pode ser necessária a indicação da eutanásia, estão os animais com doenças terminais, animais portadores de doenças zoonóticas, animais vítimas de acidentes de trânsito e como controle de excesso de animais abandonados, podendo causar sérios problemas de saúde.

Segundo os profissionais médicos veterinários entrevistados, apenas um profissional citou a eutanásia em casos de animais agressivos, enquanto $18 \%$ citaram os casos de cinomose e $46 \%$ indicaram a eutanásia em casos de outras doenças incuráveis ou em estado terminal, nos quais o animal apresenta uma situação incompatível com a vida, podendo afetar qualquer um dos sistemas (Tabela 4). 
TABELA 5: Protocolos indicados para a realização da eutanásia segundo os profissionais médicos veterinários entrevistados.

\begin{tabular}{|c|c|c|}
\hline Métodos empregados & $\begin{array}{l}\text { Número de } \\
\text { Profissionais }\end{array}$ & Porcentagem \\
\hline Acepromazina, Propofol ${ }^{1}$ e Cloreto de Potássio & 1 & $2 \%$ \\
\hline Acepromazina e Tiopental ${ }^{2}$ & 1 & $2 \%$ \\
\hline Acepromazina, Tiopental e Cloreto de Potássio & 5 & $11 \%$ \\
\hline Anestesia dissociativa (Quetamina, Xilazina) e Cloreto de Potássio & 2 & $4 \%$ \\
\hline Anestesia geral inalatória & 3 & $7 \%$ \\
\hline Anestesia geral (Tiopental) e Cloreto de Potássio & 2 & $4 \%$ \\
\hline Anestesia geral e éter endovenoso & 1 & $2 \%$ \\
\hline Anestesia geral (Tiopental ou Propofol) e Cloreto de Potássio & 19 & $42 \%$ \\
\hline Cloreto de Potássio intravenoso e intracardíaco & 1 & $2 \%$ \\
\hline Midazolan, Propofol e Cloreto de Potássio & 1 & $2 \%$ \\
\hline Sedação e choque & 1 & $2 \%$ \\
\hline Sedação e Cloreto de Potássio EV & 2 & $4 \%$ \\
\hline Sulfato de galamina e Cloreto de Potássio & 1 & $2 \%$ \\
\hline T61® & 3 & $7 \%$ \\
\hline T61® e anestesia geral & 1 & $2 \%$ \\
\hline Nenhum & 1 & $2 \%$ \\
\hline TOTALDE MÉTODOS & 45 & $100 \%$ \\
\hline
\end{tabular}

De acordo com Figueiredo; Araújo (2001), os métodos químicos de eutanásia podem ser realizados utilizando substâncias inalantes ou injetáveis, sendo a última indicada como o procedimento mais seguro e humanitário existente. Segundo Spinosa; Spinosa (2002) alguns agentes utilizados são os barbitúricos, considerados os mais próximos do ideal por serem depressores gerais do sistema nervoso central; o T-61 intravenoso e os anestésicos inalatórios.

Com relação aos métodos empregados para a realização da eutanásia, os profissionais médicos veterinários entrevistados citaram mais de um método (Tabela 5), sendo que o mais utilizado foi a anestesia geral, com Tiopental ou Propofol e Cloreto de Potássio, com 42\%; no entanto outros métodos associam ainda um sedativo antes do uso dos anestésicos gerais retromencionados podendo assim, somar suas porcentagens como nos casos em que foram citados a Acepromazina e o Midazolan como sedativos. Durante a colheita de dados 2\% dos profissionais preferiram não usar nenhum método, porque não realizavam a eutanásia na sua rotina clínica, mas indicaram o procedimento, encaminhando-o para outro colega de profissão.

Vale salientar que todos os medicamentos utilizados foram de uso endovenoso, exceto os sedativos que também podem ser utilizados vias subcutânea e intramuscular. 
TABELA 6: Destino dado ao corpo do animal eutanasiado segundo os profissionais médicos veterinários entrevistados.

\begin{tabular}{lcc}
\hline \multicolumn{1}{c}{ Destino do corpo do animal eutanasiado } & Número de casos & Porcentagem \\
\hline Crematório & 8 & $20 \%$ \\
Aterro sanitário municipal & 17 & $41 \%$ \\
Necrópsia & 2 & $5 \%$ \\
Sepultamento feito pelo proprietário & 7 & $17 \%$ \\
Sepultamento feito pelo veterinário & 3 & $7 \%$ \\
Não responderam & 4 & $10 \%$ \\
TOTAL & $\mathbf{4 1}$ & $\mathbf{1 0 0 \%}$ \\
\hline
\end{tabular}

Conforme a tabela 6 , em relação ao destino dado ao corpo do animal, $41 \%$ dos profissionais médicos veterinários consultados disseram que o corpo deve ser encaminhado para o aterro sanitário municipal como prestação de serviço oferecido pela Prefeitura Municipal. Na literatura consultada, não houve citações referentes ao destino dado ao corpo do animal eutanasiado, muito embora deve haver sempre essa preocupação, já que esses animais podem ser enterrados em locais inadequados e disseminar algumas doenças infecto-contagiosas para outros animais o ambiente ou até mesmo para os seres humanos. Este destino deveria ser discutido no âmbito da preocupação com a saúde pública, onde cada município deveria ter um regulamento para esta coleta, sendo, desta forma, um serviço supervisionado pela vigilância sanitária.

TABELA 7: Responsabilidade pelo corpo do animal eutanasiado segundo os profissionais médicos veterinários entrevistados.

\begin{tabular}{lcc}
\hline & Responsável & Número de casos \\
\hline Médico Veterinário & 15 & $37 \%$ \\
Prefeitura & 4 & $10 \%$ \\
Proprietário & 14 & $34 \%$ \\
Vigilância sanitária & 7 & $17 \%$ \\
Não responderam & 1 & $\mathbf{2} \%$ \\
TOTAL & $\mathbf{4 1}$ & $\mathbf{1 0 0 \%}$
\end{tabular}

Com relação à responsabilidade pelo corpo do animal (Tabela 7), 37\% dos entrevistados responderam que o próprio veterinário deve ser o responsável, o que nos traz novamente as questões levantadas na tabela 06 . Na literatura consultada, não houve citações referentes à responsabilidade pelo corpo do animal, no entanto o bom senso do profissional e a causa determinante para a eutanásia são relevantes para esta questão. 
TABELA 8: Informações quanto ao tipo de autorização para que o proprietário acompanhe o procedimento de eutanásia, obtidas por profissionais médicos veterinários entrevistados.

\begin{tabular}{lcc}
\hline Tipo de resposta & Número de casos & Porcentagem \\
Autorizado & 29 & $71 \%$ \\
Não autorizado & 12 & $29 \%$ \\
\hline TOTAL & 41 & $\mathbf{1 0 0 \%}$ \\
\hline
\end{tabular}

Heiblum; Tejeda (2007) mencionaram que, caso o proprietário tenha decidido pela eutanásia, o médico veterinário deve considerar quando será realizado o procedimento e se o proprietário estará presente ou não. Com relação à autorização para que o proprietário acompanhe a eutanásia, 71\% dos entrevistados dizem autorizar o acompanhamento do proprietário ao procedimento enquanto $29 \%$ não autorizam (Tabela 8 ).

TABELA 9: Informações quanto ao tipo de autorização realizada para o procedimento de eutanásia obtidas por profissionais médicos veterinários entrevistados.

Tipo de resposta

Autorização documentada

Autorização não documentada

TOTAL
Número de casos

34

7
Porcentagem

$83 \%$

$17 \%$

41

$100 \%$

Figueiredo; Araújo (2001) recomendaram que todo profissional médico veterinário, somente, realize a eutanásia após anuência, por escrito do proprietário do animal.

Com relação ao termo de autorização para eutanásia, dos quarenta e um profissionais entrevistados, $83 \%$ fazem uma autorização documentada, enquanto que $17 \%$ não fazem autorização documentada (Tabela 9). Ressalta-se aqui a importância de sempre registrar procedimentos como forma de respeitar o Código de Deontologia e Ética Profissional do Médico Veterinário.

TABELA 10: Número de profissionais médicos veterinários entrevistados, que responderam sim, não ou variável quanto à indicação da eutanásia em caso de grande incidência de abandono de animais.

\begin{tabular}{lcc}
\hline Tipo de resposta & Número de casos & Porcentagem \\
Sim & 7 & $17 \%$ \\
Não & 33 & $80 \%$ \\
Variável & 1 & $2 \%$ \\
\hline TOTAL & 41 & $\mathbf{1 0 0 \%}$ \\
\hline
\end{tabular}

Segundo Rivera et al. (2006), dentre as situações onde há necessidade de se realizar a eutanásia, encontra-se a indicação como controle de excesso de animais abandonados e que, se continuarem nas ruas poderão ocasionar sérios problemas de saúde. 
Frank (2004) ressaltou que a superpopulação de animais de companhia é um problema que acarreta significativos custos humanos, os quais poderiam ser minimizados através de ações humanas, como a castração e a adoção destes animais, reduzindo assim a prática da eutanásia.

Com relação à justificativa da prática da eutanásia em caso de grande incidência de abandono de animais, 17\% dos profissionais médicos veterinários entrevistados defenderam que a eutanásia seria justificada, $80 \%$ acharam que não, enquanto $2 \%$ disseram que esta questão é variável (Tabela 10).

Em adição, os entrevistados referiram, em todas as oportunidades, a importância da forma de se abordar a eutanásia junto ao proprietário, devendo deixar que o mesmo decida, mostre respeito ao animal, explique a necessidade do procedimento devido a prognósticos desfavoráveis, sempre com paciência e compreensão.

\section{CONCLUSÃO}

Independente do tempo de graduado e do tempo de atuação na clínica de pequenos animais, a maioria dos profissionais médicos veterinários entrevistados empregavam a eutanásia nos casos em que a afecção apresentada se tornava incompatível com a vida, trazendo sofrimento não só para o animal, mas também para seus proprietários.

O método mais utilizado para o procedimento da eutanásia é a anestesia geral barbitúrica ou não, seguida da utilização do cloreto de potássio por via intravenosa.

A maioria dos profissionais entrevistados referiram autorizar que o proprietário acompanhe a eutanásia; fazer termo de autorização documentado quando o procedimento for indicado; ficar responsável pelo corpo do animal e o encaminhar ao aterro sanitário municipal. Ainda, a maioria não concorda com a prática da eutanásia em casos de grande incidência de abandono de animais.

\section{REFERÊNCIAS}

BIRCH, J. Estudos sobre surdez: métodos de ensaio de Baer para cães e gatos de raças com risco hereditário. Dantas-Veterinário Erudito, v.87, n.11, p.14-17, 2004.

DENNLER, M. et al. Diagnóstico de Imagem-Metástase de hemangiossarcoma causando hemorragia cerebral em um cão. Ultra-som e Radiologia Veterinária, v.48, n.2, p.138-140, 2007.

FATJO, J.; RUIZ DE LA TORRE, J. L.; MANTECA, X. A epidemiologia dos problemas comportamentais em cães e gatos: um estudo de médicos veterinários. Bem-Estar Animal, v.15, n.2, p.179-185, 2006. 
FIGUEIREDO, A. C. C.; ARAÚJO, F. A. A. Eutanásia animal em centros de controle de zoonoses. Revista CFMV, Brasília, ano VII, n.23, p.12-17, Maio/Jun/Jul/Ago, 2001.

FRANK, J. Um modelo interativo da dinâmica humana e animal companheiro: a ecologia e a economia da superpopulação de cães e os custos humanos para a resolução do problema. Homem-Ecologia, v.32, n.1, p.107-130, 2004.

HEIBLUM, F. M.; TEJEDA, P. A. Eutanásia e Tanatologia em pequenos animais. Jornal de Veterinária: comportamento clínico, aplicações e investigação, v.2, n.2, p.35-39, 2007.

HUGHES, K. L.; SLATER, M. R.; HALLER, L. Os efeitos da implementação de um gato selvagem castrado: um programa na Flórida do conselho e serviço de controle animal. Jornal de Ciência Aplicada ao Bem-Estar Animal, v.5, n.4, p.285-298, 2002.

JOHANNES, C. M.et al. Hemangiossarcoma em gatos: 53 casos (1992 - 2002). Jornal da Associação Americana de Medicina Veterinária, v.231, n.12, p.1851-1856, 2007.

LAKESTANi, N. N. et al. Mordidas de cão em crianças. Jornal Europeu de Práticas de Companhia Animal, v.15, n.2, p.133-135, 2005.

MASSONE, F. Anestesiologia veterinária: farmacologia e técnicas. Rio de Janeiro: Guanabara Koogan, 2003. p.236-238.

OLIVEIRA, H. P.; ALVES, G. E. S.; REZENDE, C. M. F. Eutanásia em medicina veterinária. Disponível em: $<$ http://www.ufmg.br/coep/eutanasia.pdf> . Acesso em: 08 abr.2008.

PIIRAINEN, K.; TAPONEN, S. Problemas comportamentais como motivo de eutanásia. Super decorrente, v.109, n.3, p.132-138, 2003.

RIVERA, E. A. B.; AMARAL, M. H.; NASCIMENTO, V. P. Ética e Bioética aplicadas à Medicina Veterinária. Goiânia, 2006. p.267-298.

SPINOSA, H. S.; GÓRNIAK, S. L.; BERNARDI, M. M. Farmacologia aplicada à medicina veterinária. 3.ed. Rio de Janeiro: Guanabara Koogan, 2002. p.679-682.

Nucleus Animalium, v.1, n.1, maio 2009 


\section{ANEXO A}

\section{FUNDAÇÃO EDUCACIONAL DE ITUVERAVA \\ FACULDADE Dr. FRANCISCO MAEDA \\ ENTREVISTA COM MÉDICOS VETERINÁRIOS \\ PESQUISA DE CAMPO}

1-Quantos anos de formado você tem?
( ) até 2 anos
( ) 2 a 5 anos
( ) 6 a 10 anos
( ) 11 a 15 anos
( ) acima de 15 anos

2-A quanto tempo você trabalha com pequenos animais?
( ) até 2 anos
( ) 2 a 5 anos
( ) 6 a 10 anos
( ) 11 a 15 anos
( ) acima de 15 anos

3-Em quais casos você indicaria a prática da eutanásia?

4-Quais são os métodos empregados para a sua realização?

5-Como abordar o proprietário do animal quando há necessidade de realizar a eutanásia?

6-O que deve ser feito com o corpo do animal depois de eutanasiado?

7- O médico veterinário deve se responsabilizar pelo corpo?

8-Se o proprietário insistir em acompanhar o procedimento, você autorizaria?
( ) SIM
( ) NÃO

9-Você faz termo de autorização para eutanásia?
( ) SIM
( ) NÃO

10-A eutanásia se justificaria em caso de grande incidência de abandono de animais?
( ) SIM
( ) NÃO

(Footnotes)

1 Propofol: Anestésico geral não barbitúrico. ICI-Wellcome Zeneca.

2 Tiopental: Anestésico geral barbitúrico. ABBOTT Laboratórios do Brasil-Ltda. 